\title{
In vitro evaluation of microbial adhesion on the different surface roughness of acrylic resin specific for ocular prosthesis
}

\author{
Agda Marobo Andreotti ${ }^{1}$, Cecília Alves De Sousa ${ }^{1}$, Marcelo Coelho Goiato ${ }^{2}$, \\ Emily Vivianne Freitas da Silva ${ }^{1}$, Cristiane Duque $^{3}$, Amália Moreno $^{4}$, \\ Daniela Micheline Dos Santos ${ }^{2}$
}

Correspondence: Dr. Marcelo Coelho Goiato

Email: goiato@foa.unesp.br
'Department of Dental Materials and Prosthodontics, Aracatuba Dental School, Universidade Estadual Paulista (UNESP), Aracatuba, Sao Paulo, Brazil,

${ }^{2}$ Bucal Oncology Center, Aracatuba Dental School, Universidade Estadual Paulista (UNESP), Aracatuba, Sao Paulo, Brazil,

${ }^{3}$ Department of Pediatric Dentistry, Aracatuba Dental School, Universidade Estadual Paulista (UNESP), Aracatuba, Sao Paulo, Brazil,

${ }^{4}$ Department of Oral Surgery and Pathology, School of Dentistry, Federal University of Minas Gerais, Belo Horizonte, Minas Gerais, Brazil

\section{ABSTRACT}

Objective: The purpose of this study was to evaluate the influence of surface roughness in biofilm formation of four microorganisms (Staphylococcus epidermidis, Staphylococcus aureus, Enterococcus faecalis, and Candida albicans) on acrylic resin surface of ocular prostheses. Materials and Methods: Acrylic resin samples were divided into six groups according to polishing: Group 1200S (1200 grit + silica solution); Group 1200; Group 800; Group 400; Group 120 and Group unpolished. Surface roughness was measured using a profilometer and surface images obtained with atomic force microscopy. Microbial growth was evaluated after 4, 24, and 48 hours of incubation by counting colony-forming units. Statistical Analysis Used: For roughness, it was performed 1-way ANOVA and parametric Tukey test $\alpha 5 \%(P \leq 0.05)$. For CFU data found, it was applied Kruskal-Wallis and Mann-Whitney tests. Results: Group 120 and 400 presented the highest roughness values. For S. epidermidis and S. aureus, Group 1200S presented the lowest values of microbial growth. For E. faecalis at 4 hour, microbial growth was not observed. C. albicans did not adhere to the acrylic resin. Except for Group 1200S, different surface roughnesses did not statistically interfere with microbial adhesion and growth on acrylic surfaces of ocular prostheses. Conclusions: The roughness did not interfere with the microbial adhesion of the microorganisms evaluated. The use of silica decreases significantly microbial growth.

Key words: Acrylic resin, biofilm, microbial adhesion, ocular prosthesis

\section{INTRODUCTION}

An ocular prosthesis is an option for rehabilitation of

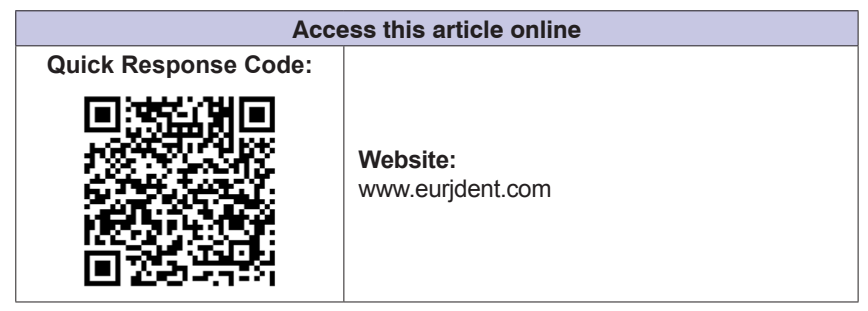

This is an open access journal, and articles are distributed under the terms of the Creative Commons Attribution-NonCommercial-ShareAlike 4.0 License, which allows others to remix, tweak, and build upon the work non-commercially, as long as appropriate credit is given and the new creations are licensed under the identical terms.

For reprints contact: reprints@medknow.com 
anophthalmic patients, being fabricated principally from acrylic resin. Although the ocular prosthesis can be adopted adequately in the anophthalmic cavity, in the majority of cases a "dead space" is observed between the posterior surface and the bottom of the cavity. Lacrimal secretion, mucous, and stagnant residue in this space constitutes an excellent culture environment for the growth of bacteria. ${ }^{[1]}$

One of the most important pathogens of prosthetic infections is the Staphylococcus. ${ }^{[2]}$ Staphylococcus epidermidis can adhere and proliferate on polymer surfaces, especially on lenses and intraocular prostheses. ${ }^{[3,4]}$ Staphylococcus aureus lives principally on mucous surfaces and is considered as one of the most versatile and dangerous human pathogens. ${ }^{[5]}$ Enterococcus faecalis is a natural Gram-positive streptococcal of the intestinal tract, able to cause serious infections such as endophthalmitis and corneal ulcers. ${ }^{[6,7]}$ Another microorganism encountered in the ocular region is Candida albicans, which also occurs among the fungal infections of maxillofacial prostheses. ${ }^{[8]}$ The hematogenic dissemination of C. albicans to the eye is associated with intravenous drug abuse, grave debilitation, or immunodepression, recent surgery (especially gastrointestinal), the use of broad-spectrum antibiotics, diabetes, and alcohol abuse, among others. ${ }^{[9,10]}$

Recently, a large number of reports in respect to the impact of the physical properties of the materials in the adhesion of microbe, ${ }^{[11-17]}$ and a particularly strong relation between the bacterial adhesion and surface roughness, have been highlighted. ${ }^{[14-18]}$ The surface roughness of the material is considered a relevant property for the process of microbial adhesion. This is because polymer surface irregularities, such as grooves or fissures, promote an increase in the surface area, and depressions that provide more favorable sites for colonization which protect the microbe against the forces of shearing. ${ }^{[11,19]}$ Since the behavior of microbial adhesion on polymers depends on the microorganism colonizer and the surface roughness of the material, it is important to evaluate the relation of the surface roughness of acrylic resins for ocular prostheses in the adhesion of different microorganisms.

Therefore, this study has the objectives of simulating different surface roughnesses of acrylic resins used in the fabrication of artificial sclera for ocular prostheses, and to evaluate the interference of roughness on the adhesion and formation of biofilm of different microorganisms (S. epidermidis, S. aureus, E. faecalis and
C. albicans). The null hypotheses of this study were that the surface roughness of acrylic resin does not differ among the different kinds of surface polishings and that the adhesion of microorganisms would not be influenced by the roughness of the acrylic resin.

\section{MATERIALS AND METHODS}

For the fabrication of the test specimens in acrylic resin, a molded metallic matrix was used which contained ten circular compartments in its interior, each with dimensions of $10 \mathrm{~mm}$ diameter and $3 \mathrm{~mm}$ thickness. The matrix adhered to a rectangular glass slide. The glass slide and matrix set were then placed in a special muffle for polymerization in a microwave oven (VIPI STG; VIPI Industria, Pirassununga, Sao Paulo, Brazil), filled with special plaster Type IV (Durone; Dentsply Ind and Com Ltd, Rio de Janeiro, Brazil). After the plaster crystallized, another glass slide was positioned over the already enclosed matrix, a contra muffle was positioned, and special plaster type IV was poured over the surface of the last glass slide. The muffle was opened after the crystallization, and the N1 heat-activated acrylic resin (white color) for artificial sclera (Artigos Odontologicos Classico Ltda., Sao Paulo, Brazil) was proportioned, manipulated, and inserted in the matrix. After the insertion, the contra muffle was positioned and carried to a hydraulic press, (VH; Midas Dental Produtos Ltda., Araraquara, São Paulo, Brazil) and placed under a force of $1200 \mathrm{~kg} / \mathrm{F}$ for $2 \mathrm{~min}$. Subsequently, a $30 \mathrm{~min}$ bench polymerization was performed, followed by a $10 \mathrm{~min}$ microwave polymerization. After the resin polymerization, the muffle was opened, and the specimens were removed. The specimens were then submitted to polishing for 3 min using metallographic sandpaper of different granulations (Buehler, Illinois, USA). Blue colloidal silica solution (Buehler, Illinois, USA) with a grain of 1 micrometric $(\mu \mathrm{m})$ was used on one group. After polishing, ultrasound cleaning was performed to remove possible debris.

A total of 432 test specimens were fabricated. Of these, 144 were divided for the periods of 4,24 , and $48 \mathrm{~h}$ of microbial growth and adhesion. Thirty-six test specimens were inoculated with one of the four microorganisms evaluated. For each microorganism, the test specimens were distributed randomly in six groups (6 specimens per group with 3 for each experiment): Group 1200S: polished with 1200-grain sandpaper and the diamond solution of $1 \mu \mathrm{m}$; Group 1200: polished with 1200-grain sandpaper; 
Group 800: polished with 800-grain sandpaper; Group 400: polished with 400-grain sandpaper; Group 120: polished with 120-grain sandpaper; and Group unpolished. After the surface polishing, the test specimens were sterilized with ethylene oxide.

Strains of S. epidermidis (ATCC 35984); S. aureus (ATCC29213); E. faecalis (ATCC 29212) and C. albicans (ATCC 90028) were used. All strains were donated by the Oswaldo Cruz Foundation- FIOCRUZ, Rio de Janeiro, Brazil. The microorganisms were maintained at $-70^{\circ} \mathrm{C}$ in a solution containing $25 \%$ glycerol, seeded in plates containing culture medium adequate for each microorganism, and incubated aerobiotically at $37^{\circ} \mathrm{C}$ for $24 \mathrm{~h}$. The culture mediums used were as follows: Mannitol Salt Agar (Difco, Kansas City, MO, USA) for S. epidermidis and S. aureus; m-Enterococcus Agar (Difco, Kansas City, MO, USA), for E. faecalis, and Sabouraud Dextrose Agar (Difco, Kansas City, MO, USA) for C. albicans.

Initially, growth curves were performed for each microorganism with the purpose of identifying the number of hours necessary for each to achieve its greatest microbial multiplication phase (log phase), which was determined by the optic density values. The cultures were then seeded in BHI broth (Difco) or Sabouraud Dextrose and maintained at $37^{\circ} \mathrm{C}$ in an aerobiotic incubator for $24 \mathrm{~h}$. The microorganisms were adjusted halfway through the logarithmic phase, being diluted $\times 10, \times 100$, or $\times 100$ in BHI broth with $\times 2$ concentration, depending on each microorganism, to obtain $10^{7}$ microorganisms $/ \mathrm{ml}$.

Aftergrowthand obtainment of $10^{7}$ microorganisms $/ \mathrm{ml}$, $1 \mathrm{ml}$ of medium containing the microorganism that was used was placed in contact with the acrylic resin test specimens positioned in 24-well microtiter plates. Microbial suspensions were incubated in wells without the test specimen for negative control. The positive control of this study was the BHI broth or sabouraud dextrose for the tests with C. albicans without the microorganism. The wells were incubated at $37^{\circ} \mathrm{C}$ in an aerobiotic incubator for 4,24 , and $48 \mathrm{~h}$. After each period, the nonadhering microorganisms were removed from the test specimens by way of a wash in $1 \mathrm{ml}$ of saline solution. Subsequently, each test specimen was inserted in a test tube containing $1 \mathrm{ml}$ of saline solution. The tubes underwent an ultrasound (USC 700; UNIQUE Ultrasonic Cleaner, Sao Paulo, Brazil) cleaning bath at $50 \mathrm{kHz}, 150 \mathrm{~W}$, for $20 \mathrm{~min}$, and agitation (Vortex QL- 901; Biomixer, Curitiba, Parana, Brazil) for $1 \mathrm{~min}$, to promote detachment of adhered microorganisms. Subsequently, a series of seven dilutions were performed, transferring $10 \mathrm{ul}$ of this solution to $90 \mathrm{ul}$ of saline solution. Dilutions 4 and 7 were plated in petri plates containing an adequate medium for each microorganism evaluated, and incubated for $37^{\circ} \mathrm{C}$ in an aerobiotic incubator for $24 \mathrm{~h}$. After the incubation period, the counting of the colony-forming units $(\mathrm{CFU} / \mathrm{mL})$ was done. The tests were performed in duplicate on two independent days.

The surface roughness of all test specimens was determined using a profilometer (Dektak d-150; Veeco, Plainview, New York, USA). One test specimen was positioned individually in the center of the equipment, and the profilometer measuring tip was focused on its surface. The Ra (surface roughness arithmetic mean) values were measured using a cut-off of $500 \mu \mathrm{m}$ in a 12s time constant. Three readings were performed on each surface, and the mean was calculated. The original values were given in Angstrom $(\AA)$, and were then transformed to the $\mu \mathrm{m}$ scale.

A test specimen from each sandpaper polish group was analyzed using atomic force microscopy (AFM; Veeco Metrology Inc., Santa Barbara, CA, USA). The images obtained were transported from the microscope to a computer. Subsequently, they were sent to the NanoScope Analysis program (2004; Veeco Instruments Inc., Santa Barbara, CA, USA) and submitted to filters ("lowpass" and "medium"). All three-dimensional (3D) images were standardized in the minimum height scale of $-100 \mathrm{~nm}$ and a maximum of $100 \mathrm{~nm}$ (z-axis) for later qualitative comparison among the groups.

The surface roughness value and test specimen microorganism count for each group, as well as the time of incubation and type of microorganism, were submitted to the normal curve adherence test to determine if they provided a normal distribution. A normal distribution for roughness values was found, consequently performing a one-way ANOVA and parametric Tukey test with a 5\% $(P \leq 0.05)$ level of significance. A nonnormal distribution for CFU data was also found and hence, appropriate nonparametric statistic tests were applied to compare the measurements through the Kruskal-Wallis and Mann-Whitney tests.

\section{RESULTS}

Using the one-way ANOVA, it was observed that there was a significant statistical difference 
comparing the Ra roughness values obtained by the different polishings $(\mathrm{F}=1361.651 ; P \leq 0.001)$, with the 120 and 400 groups differentiated statistically between themselves and in relation to all the other groups, with Group 120 presenting the greatest Ra roughness value, followed by Group 400. The nonpolished group did not differ statistically from Group 800, 1200, or 1200S [Table 1].

The qualitative analysis regarding the surface smoothness of 3D images of the study reveals apparent differences in the images, as to the formation of irregularities along the extensions evaluated. Groups 120 and 400 present images that reveal irregularities with more significant cracks and

\begin{tabular}{lc}
$\begin{array}{l}\text { Table 1: Mean values (standard deviation) of Ra } \\
\text { roughness of acrylic resin, according to polishing } \\
\text { sandpaper used }\end{array}$ \\
\hline \multicolumn{2}{c}{ Acrylic resin } \\
\hline Groups & Ra roughness \\
\hline Unpolished & $0.05(0.04) \mathrm{C}$ \\
120 & $1.72(0.36) \mathrm{A}$ \\
400 & $0.52(0.12) \mathrm{B}$ \\
800 & $0.03(0.01) \mathrm{C}$ \\
1200 & $0.02(0.01) \mathrm{C}$ \\
$1200 \mathrm{~s}$ & $0.03(0.01) \mathrm{C}$ \\
\hline
\end{tabular}

Means followed by the same capital letter in column do not differ at the $5 \%$ significance level ( $P<0.05$; Tukey) orifices. These include the interior of a crack with the formation of a deeper "valley" without the definition of the highest point above the "peaks," as compared to those that still maintain the characteristic of a polished surface (800,1200, and 1200S, and nonpolished), although the nonpolished group presented small irregularities on its surface [Figure 1 1.1-1.6].

Figures 2 and 3 show the microbial growth values for the bacterial species. It can be observed that for S. epidermidis, all of the groups differentiate from the control group at 4 and $48 \mathrm{~h}$. Group $1200 \mathrm{~S}$ differentiated from the control in all time periods and had the smallest bacterial growth values after 24 and $48 \mathrm{~h}$ of growth [Figure 2].

Figure 4 shows that for S. aureus, only Group 1200 S presented the smallest bacterial growth values, with the statistical difference about the control.

For E. faecalis, it was observed that the initial adhesion probably took more than $4 \mathrm{~h}$ to occur since there was no microorganism growth observed in this period. In addition, except Group 400 at $48 \mathrm{~h}$, all the materials differentiated from the control, but not among themselves [Figure 3].

Adhesion of C. albicans was not observed on the acrylic resin surfaces evaluated.

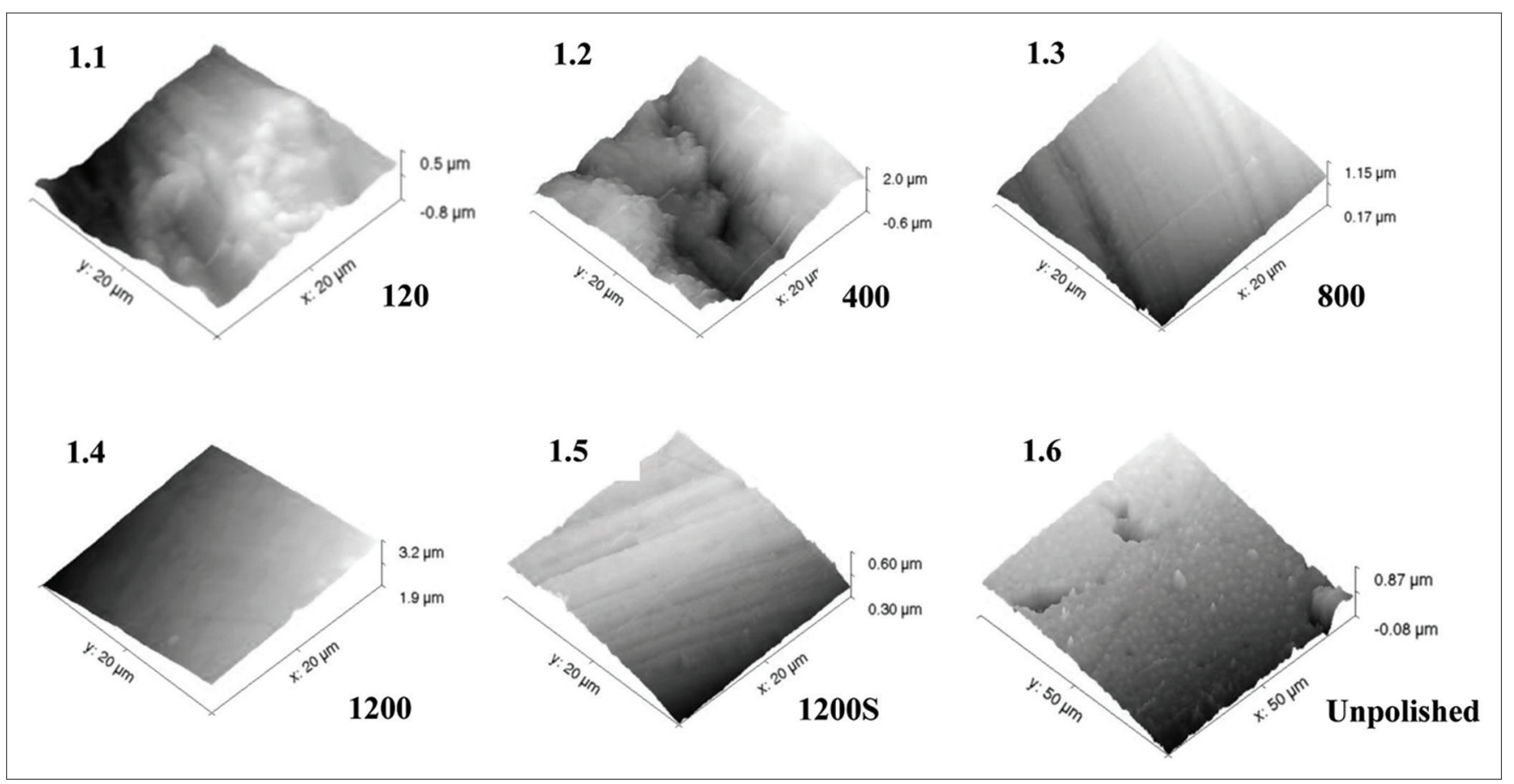

Figure 1: Representative atomic force microscopy image. 1.1 represents the Group 120 and 1.2 represents the Group 400 at the both images irregular surfaces are evident. 1.3 represents the Group 800; 1.4 represents the Group 1200 and 1.5 represents the Group 1200s at this images the characteristics of polished surfaces were maintained. 1.6 represents the Group Unpolished, which presents smooth surface with the presence of some peaks and valleys 


\section{DISCUSSION}

The first hypothesis of this study that the different acrylic resin surface roughnesses do not interfere with the growth of microorganisms was confirmed by the fact that there were no significant differences among the different polish groups. The second hypothesis that the different sandpaper grains for polishing do not promote significant differences in the surface

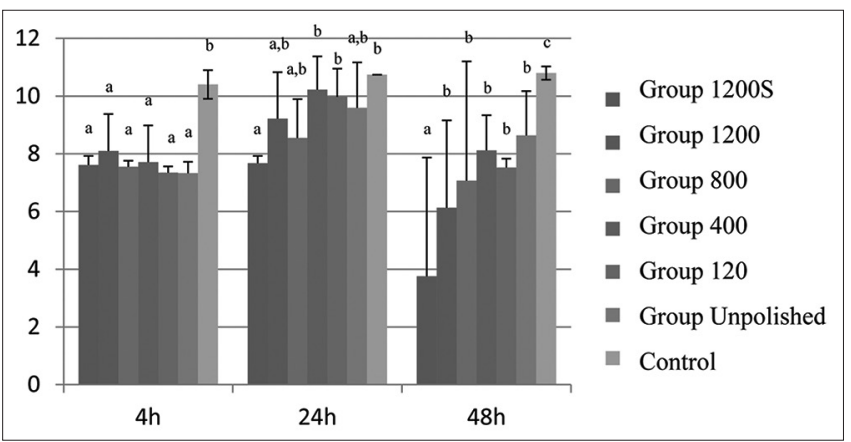

Figure 2: Mean (standard deviation) of colony-forming unit/ml count (in logarithmic scale) of Staphylococcus epidermidis for each granulation group. a: Different lowercase letters show statistical difference between each group, according to the Mann-Whitney tests, considering $P \leq 0.05$

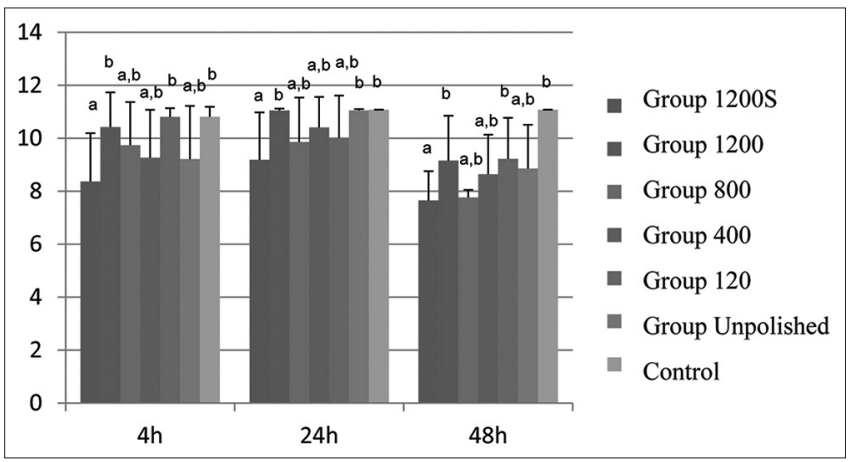

Figure 3: Mean (standard deviation) of colony forming unit $/ \mathrm{ml}$ count (in logarithmic scale) of Enterococcus faecalis for each granulation group. a: Different lowercase letters show statistical difference between each group, according to the Mann-Whitney tests, considering $P \leq 0.05$

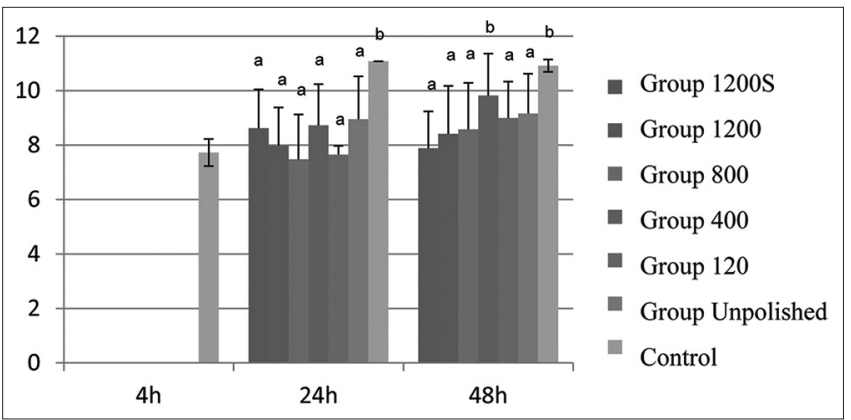

Figure 4: Mean (standard deviation) of colony-forming unit/ml count (in logarithmic scale) of Staphylococcusaureus for each granulation group. a: Different lowercase letters show statistical difference between each group, according to the Mann-Whitney tests, considering $P \leq 0.05$ roughness values was partially accepted since there was a significant statistical difference for E. faecalis in the growth of microorganisms in the group polished with 400 grain sandpaper. The bacterial growth model used in this study simulated in vitro conditions of static biofilm growth that is encountered on the contact surface of an ocular prosthesis with the conjunctive membrane tissue.

The initial microorganism adhesion to the surface of the materials is the key requirement for the colonization of the material. ${ }^{[19,20]}$ When a bacterium adheres and proliferates on the surface of a material, it produces extracellular polymer substances and forms the biofilm, which covers and protects against the immune systems and antimicrobial agents. ${ }^{[18]}$ During the process of adhesion, the bacteria adheres firmly to the surface of the material through physicochemical interactions which include the hydrophobicity and charge of the cell surface, as well as the chemical composition and the surface roughness of the material. ${ }^{[19,21]}$

Several published studies showed that in vivo bacterial adhesion is determined primarily by a Ra surface roughness $>0.2 \mu \mathrm{m} \cdot{ }^{[18,22-25]}$ However, this study observed that, in general, even the groups with lower mean Ra values $(0.02,0.03$, and 0.05$)$ demonstrated bacterial growth [Table 1 and Figures 2-4]. This data corroborate with Yoda et al., ${ }^{[18]}$ which evaluated the adhesion of microorganisms on surfaces of different biomaterials and obtained a result which showed that even surfaces with roughness levels below $30 \mathrm{~nm}(0.03 \mu \mathrm{m})$ could promote bacterial adhesion. In addition, Lee et al. ${ }^{[26]}$ observed bacterial growth with roughness levels below $0.2 \mu \mathrm{m}$ on composite resin $(\mathrm{Ra}=0.179)$, titanium $(\mathrm{Ra}=0.059)$, and zirconia $(\mathrm{Ra}=0.064)$ surfaces.

These affirmations indicate that there is no consensus with regard to the minimum roughness level for microbial adhesion and could differ according to the material used and the capacity of the microorganism to adhere to different surfaces. Thus, bacterial adhesion is a multifactorial phenomenon, and surface roughness is not the only influential characteristic in the process. ${ }^{[18]}$ In this way, other factors are also connected to the potential microbial adhesion to the acrylic resin surface, such as hydrophobicity, electrostatic interactions, and surface energy. ${ }^{[27]}$ The chemical composition of the material, the adhesion capacity level, and the size and mode of microorganism division also play a role. These factors could explain why E. faecalis took more 
time to adhere to the acrylic resin surface [Figure 3] compared with the staphylococcus since the later presented a characteristic of early adhesion. ${ }^{[19]}$

Published studies report that microorganisms appear to have a preference for adhesion on rougher surfaces with scratches and grooves. ${ }^{[19]}$ However, the current study observed that except Group 1200S, which received polishing with 1200-grain sandpaper and silicone-based diamond solution, the other groups did not differ among themselves as far as the bacterial growth values [Figures 2-4]. This data corroborate with Taha et al., ${ }^{[23]}$ which evaluated microorganism adhesion, including S. aureus and C. albicans on 3 types of orthodontic wire with different roughnesses, and did not encounter a significant difference among the groups.

In agreement with the results of the current study, some authors ${ }^{[28-31]}$ reported that a linear relation between bacterial adhesion and surface roughness is not always observed. A small increase in roughness could lead to a significant increase in bacterial adhesion, while a large increase in roughness might not have a significant effect on adhesion. ${ }^{[19]}$ Previous published studies ${ }^{[24,25]}$ reported that small variations of surface roughness do not present a significant effect on bacterial adhesion, which could justify the absence of a significant relationship between microbial adhesion and the roughness observed in this study. ${ }^{[23]}$

Although the AFM images show a certain irregularity in the surface of the nonpolished group [Figure 1f], the Ra mean value of this group was low and similar to the 800,1200 , and 1200 S Groups [Table 1]. Still, the nonpolished group did not differ statistically for the polished group about bacterial growth [Figures 2-4]. This data could have resulted from the compression of the acrylic resin against a glass slide at the moment of fabrication of the test specimens with polish, which could have resulted in a smooth surface similar to the groups that received refined polishing, and thus, similar roughness and bacterial growth values were observed. ${ }^{[22,32]}$

It was observed that the group with more refined polishing (1200S) was statistically different from the control for all periods and bacteria evaluated, principally for S. epidermidis and S. aureus. In general, this group presented smaller values of bacterial growth, although it can be observed in the AFM images $^{[33]}$ and the Ra roughness values that there was no difference about the 800, 1200, and nonpolished groups [Table 1 and Figures 1-4]. This result could have occurred due to the silicone ion (Si) implantation present in the diamond solution used in the polishing of this group, which made the surface less susceptible, affecting the adhesion process. The $\mathrm{Si}$ ion can reduce the surface energy and the contact angle, influencing the wettability and hampering the adhesion of microorganisms. The result obtained is in agreement with the studies of Zhao, in which it was observed that there was a reduction in microorganism adhesion in the presence of $\mathrm{SiF} 3$ in stainless steel. ${ }^{\left[{ }^{[32]}\right.}$ In addition, Rashid et al. ${ }^{[34]}$ reported that the use of the diamond solution for polishing favored the prevention of microorganism accumulation on the surface of the materials.

An interesting fact observed in the results of the current study, which differs from the majority of studies encountered ${ }^{[27,35,36]}$ was that the C. albicans did not adhere to the surfaces of the test specimens, independent of the polishing realized. ${ }^{[37]}$ The low indices of $C$. albicans adhesion may be associated with the morphology of the fungus. This may be because $C$. albicans fungus is large $(4-6 \mu \mathrm{m})^{[35]}$ and possess long filaments in their shapes, limiting adhesion to the narrow recess of surface cracks, making it less stable. ${ }^{[34]}$ It is known that the presence of bacteria facilitates the adhesion of Candida fungus to acrylic resin, principally through the production of extracellular polymers as well as through an increase in acidity, which creates favorable environmental conditions for the growth of fungus. ${ }^{[36,38]}$ In this study, however, isolated biofilms of each microorganism were evaluated, and in this way, the C. albicans strains could not count on the presence of other microorganisms to aid in their growth.

Although the results of this study revealed a weak relation between surface roughness and microbial adhesion, the stages of polishing during the fabrication of ocular prostheses should not be overlooked, since bacterial adhesion is not determined only by this isolated property. In addition, roughness should never be considered alone about microbial adhesion. Other factors are also associated with this property, such as comfort and satisfactory esthetics of the patient.

Diverse limitations should be considered to interpret the results. The pathogenicity of prosthetic devices is a complex process involving interactions between the pathogen, material, and the host. An in vitro study 
cannot count on the defense of the host and other factors such as fluctuation of temperature conditions and nutrition. ${ }^{[18]}$

\section{CONCLUSIONS}

Thus, considering the limitations described, and even though, the low values of roughness obtained through different polishings could have been important in preventing the adhesion of $C$. albicans, it can be concluded that the small variations in acrylic resin surface roughness did not produce differences in adhesion or formation of biofilms of the bacteria evaluated. This suggests that roughness is not the only property that should be considered when evaluating microbial adhesion. Silica appears to interfere with microorganism adhesion since microbial growth decreases significantly compared with other groups and the control group when silica solution is associated with polishing.

\section{Acknowledgments}

The authors acknowledge the CNpQ for financial support (protocol 2014/29375).

The authors thank PIBIC-CNPq (National Council for Scientific and Technological Development) 2014/29375 for the scholarship granted to Cecília Alves de Sousa.

\section{Financial support and sponsorship \\ Nil.}

\section{Conflicts of interest}

There are no conflicts of interest.

\section{REFERENCES}

1. Dayal Y, Rao SS, Mahajan VM. Comparative study of bacterial and fungal floras of contracted sockets and fellow eyes. Ann Ophthalmol 1984;16:154, 156, 158.

2. Arciola CR, Campoccia D, Speziale P, Montanaro L, Costerton JW. Biofilm formation in Staphylococcus implant infections. A review of molecular mechanisms and implications for biofilm-resistant materials. Biomaterials 2012;33:5967-82.

3. Veyries ML, Faurisson F, Joly-Guillou ML, Rouveix B. Control of staphylococcal adhesion to polymethylmethacrylate and enhancement of susceptibility to antibiotics by poloxamer 407. Antimicrob Agents Chemother 2000;44:1093-6.

4. Vacheethasanee K, Marchant RE. Surfactant polymers designed to suppress bacterial (Staphylococcus epidermidis) adhesion on biomaterials. J Biomed Mater Res 2000;50:302-12.

5. Singh D, Kaur H, Gardner WG, Treen LB. Bacterial contamination of hospital pagers. Infect Control Hosp Epidemiol 2002;23:274-6.

6. Rishi E, Rishi P, Nandi K, Shroff D, Therese KL. Endophthalmitis caused by Enterococcus faecalis: A case series. Retina 2009;29:214-7.

7. Peng $\mathrm{CH}$, Cheng CK, Chang CK, Chen YL. Multiresistant enterococci: A rare cause of complicated corneal ulcer and review of the literature. Can J Ophthalmol 2009;44:214-5.

8. Paranhos RM, Batalhão $\mathrm{CH}$, Semprini M, Regalo SC, Ito IY, de Mattos Mda G, et al. Evaluation of ocular prosthesis biofilm and anophthalmic cavity contamination after use of three cleansing solutions. J Appl Oral Sci 2007;15:33-8.

9. Scherer WJ, Lee K. Implications of early systemic therapy on the incidence of endogenous fungal endophthalmitis. Ophthalmology 1997;104:1593-8.

10. Williams MA, McMullan R, Hedderwick S, Mulholland DA, Best RM. Diagnosis and treatment of endogenous fungal endophthalmitis. Ophthalmologica 2006;220:134-6.

11. Katsikogianni M, Missirlis YF. Concise review of mechanisms of bacterial adhesion to biomaterials and of techniques used in estimating bacteria-material interactions. Eur Cell Mater 2004;8:37-57.

12. Busscher HJ, van der Mei HC. Physico-chemical interactions in initial microbial adhesion and relevance for biofilm formation. Adv Dent Res 1997;11:24-32.

13. Gottenbos B, Van Der Mei HC, Busscher HJ, Grijpma DW, Feijen J. Initial adhesion and surface growth of Pseudomonas aeruginosa on negatively and positively charged poly (methacrylates). J Mater Sci Mater Med 1999;10:853-5.

14. Scheuerman TR, Camper AK, Hamilton MA. Effects of substratum topography on bacterial adhesion. J Colloid Interface Sci 1998;208:23-33.

15. Teughels W, Van Assche N, Sliepen I, Quirynen M. Effect of material characteristics and/or surface topography on biofilm development. Clin Oral Implants Res 2006;17 Suppl 2:68-81.

16. Subramani K, Jung RE, Molenberg A, Hammerle CH. Biofilm on dental implants: A review of the literature. Int J Oral Maxillofac Implants 2009;24:616-26.

17. Quirynen M, van der Mei HC, Bollen CM, Schotte A, Marechal M, Doornbusch GI, et al. An in vivo study of the influence of the surface roughness of implants on the microbiology of supra- and subgingival plaque. J Dent Res 1993;72:1304-9.

18. Yoda I, Koseki H, Tomita M, Shida T, Horiuchi H, Sakoda H, et al. Effect of surface roughness of biomaterials on Staphylococcus epidermidis adhesion. BMC Microbiol 2014;14:234.

19. Sousa C, Teixeira P, Oliveira R. Influence of surface properties on the adhesion of Staphylococcus epidermidis to acrylic and silicone. Int J Biomater 2009;2009:718017.

20. Loney RW, Moulding MB, Hacker CH, Ritsco RG. Finishing and polishing of a poly (fluoroalkoxyphosphazene) resilient denture liner. Int J Prosthodont 1994;7:362-7.

21. An YH, Friedman RJ. Concise review of mechanisms of bacterial adhesion to biomaterial surfaces. J Biomed Mater Res 1998;43:338-48.

22. Bollen CM, Lambrechts P, Quirynen M. Comparison of surface roughness of oral hard materials to the threshold surface roughness for bacterial plaque retention: A review of the literature. Dent Mater 1997;13:258-69.

23. Taha M, El-Fallal A, Degla H. In vitro and in vivo biofilm adhesion to esthetic coated arch wires and its correlation with surface roughness. Angle Orthod 2016;86:285-91.

24. Bollen CM, Papaioanno W, Van Eldere J, Schepers E, Quirynen M, van Steenberghe D, et al. The influence of abutment surface roughness on plaque accumulation and peri-implant mucositis. Clin Oral Implants Res 1996;7:201-11.

25. Quirynen M, Bollen CM. The influence of surface roughness and surface-free energy on supra- and subgingival plaque formation in man. A review of the literature. J Clin Periodontol 1995;22:1-4.

26. Lee BC, Jung GY, Kim DJ, Han JS. Initial bacterial adhesion on resin, titanium and zirconia in vitro. J Adv Prosthodont 2011;3:81-4.

27. Zamperini CA, Carneiro Hde L, Rangel EC, Cruz NC, Vergani CE, Machado AL, et al. In vitro adhesion of Candida glabrata to denture base acrylic resin modified by glow-discharge plasma treatment. Mycoses 2013;56:134-44

28. Taylor RL, Verran J, Lees GC, Ward AJ. The influence of substratum topography on bacterial adhesion to polymethyl methacrylate. J Mater Sci Mater Med 1998;9:17-22.

29. Lee HJ, Park HS, Kim KH, Kwon TY, Hong SH. Effect of garlic on bacterial biofilm formation on orthodontic wire. Angle Orthod 2011:81:895-900.

30. Lee HJ, Park HS, Kim KH, Kwon TY, Hong SH. Surface characteristics of orthodontic materials and their effects on adhesion of mutans streptococci. Angle Orthod 2011;81:895-900.

31. Kim IH, Park HS, Kim YK, Kim KH, Kwon TY. Comparative short-term in vitro analysis of mutans streptococci adhesion on esthetic, nickel-titanium, and stainless-steel arch wires. Angle Orthod 2014;84:680-6. 
32. Garrett TR, Bhakoob M, Zhanga Z. Bacterial adhesion and biofilms on surfaces. Prog Nat Sci 2008;10:1049-56.

33. Germano F, Bramanti E, Arcuri C, Cecchetti F, Cicciù M. Atomic force microscopy of bacteria from periodontal subgingival biofilm: Preliminary study results. Eur J Dent 2013;7:152-8.

34. Zhao Q, Liu Y, Wang C, Wang S, Peng N, Jeynes C, et al. Reduction of bacterial adhesion on ion-implanted stainless steel surfaces. Med Eng Phys 2008;30:341-9.

35. Rashid H. The effect of surface roughness on ceramics used in dentistry: A review of literature. Eur J Dent 2014;8:571-9.

36. Silva S, Pires P, Monteiro DR, Negri M, Gorup LF, Camargo ER, et al.
The effect of silver nanoparticles and nystatin on mixed biofilms of Candida glabrata and Candida albicans on acrylic. Med Mycol 2013;51:178-84.

37. Rosa MB, Albrektsson T, Francischone CE, Schwartz Filho HO, Wennerberg A. The influence of surface treatment on the implant roughness pattern. J Appl Oral Sci 2012;20:550-5.

38. Izumida FE, Moffa EB, Vergani CE, Machado AL, Jorge JH, Giampaolo ET, et al. In vitro evaluation of adherence of Candida albicans, Candida glabrata, and Streptococcus mutans to an acrylic resin modified by experimental coatings. Biofouling 2014;30:525-33. 